\title{
A Novel Method in Food Safety Management by Using Case Base Reasoning Method
}

\author{
S. Saqaeeyan \\ Department of Computer, Abadan Branch, Islamic Azad University, Abadan, Iran \\ E-mail: sasan_sagha@yahoo.com
}

\author{
A. Rismantab \\ Sama technical and vocational training college Islamic Azad University, Shushtar Branch, Shushtar, Iran \\ E-mail:alirismantab@gmail.com
}

\begin{abstract}
Today's Food Industry has responsibility to provide most consuming food for people. These foods are consumed by large area of society. So they are important source of causes of diseases and food poisoning. Monitoring system have been created to control these diseases and they are used in duration of production step of food supply chain. Hazard Assurance Critical Control Point (HACCP) is regarded as best method in safety system. Necessity to create integrated HACCP system forced factories to use intelligent methods to build HACCP for every production. This paper proposes CaseBased Reasoning (CBR) technique and use of paired comparisons tables and similarity equations to create HACCP for food system of Sabz Nam Company. Our system is an intelligent system has based on RFID and it works as consulter by generating five proper safety suggestion to food expert. Finally we assess accuracy and efficiency of proposed system on real data of Sabz Nam Company.
\end{abstract}

Index Terms-Food Safety, Hazard Analysis and Critical Control Points (HACCP), Case Base Reasoning (CBR), Radio-frequency identification (RFID), Expert system, Data Base.

\section{INTRODUCTION}

Food preservation is vital to safety and requires careful and strategic methods due to foods have short life and they are rotten very fast and food poisoning occur easily [1].

In order to protect health of consumers, various regulations have developed to control quality of food products in fact, food safety should be considered in all parts of the food chain from raw material stage to canning and storage of food [2]. One of specific monitoring system that can be used during process of production is HACCP. Nowadays HACCP is considered as a prerequisite for food manufacturers before to enter international market [3]. In my country, Iran, HACCP has been developed under standard No.4557. All companies and food industry must abide these rules. A food safety program is included potential risks, check points, critical control points, control limits, and monitoring procedures and corrective action. For developing these elements a several metrics such as analysis of potential risk of a food product, identify all check points and critical food safety and etc. are required [4]. Human person was traditionally involved in the process of deciding for future of food safety. But when inventories are high, decisions about food storage conditions will be difficult and it require an expert person [5].So decisions are depend on skill of person, procedures, company rules, regulations food and manual operation [6]. Companies have recently developed a unique system of decision-makers to provide electronic help. Each company has different option for its decision-making [7]. In this paper, we investigate Sabz Nam Company food productions. Attributes of these products are: maximum humidity, temperature maintenance, type of material, condition maintenance .we will create HACCP for every product by use of CBR methods and RFID to facilitate the inventory datacapturing process and assist in formulating decisions to help expert to make decisions.

The remainder of this paper is organized as follows: section 2 is about related work and Section 3 gives description of CBR. Section 4 describes the RFID. Section 5 presents our new model, experiments and evaluation. Conclusion and future work are given in the final section.

\section{RELATED WORK}

In recent years, several companies have invested to build an intelligent system of HACCP guides.one of them is production and maintenance of wine companies is in Hong Kong. Due to exposure of products, company produce specific HACCP rules. Wines get their guide base on physical characteristics including size, package type, color, and condition of package. If wine is entered without guidance a software system will use genetic algorithms and clustering to find guidance and cluster it with most similar features of previous products. This system can be used as a reliable guide for warehouse operator [8].

RFID tags with sensor embedded have recently been developed to capture various real-time data such as temperature and humidity. Another company in Hong 
Kong, due to variety of meat, dairy foods, their different conditions of storage and distribution has created a system offering products with HACCP manual that is known as RFID-FOAS. This system has ability to collect data from imported products via RFID tags into warehouse. For each product HACCP manual is used with its output. Operator who has knowledge of this guide can correctly decide to store products. Advantages of this system are: use of decision trees and optimal paired comparisons tables [9].

\section{The CAse Base Reasoning (CBR) Method}

Various CBR approaches are based on using of response of previous problems to solve new similar problems. CBR models get pattern of human behavior in dealing with new problems. Experiences are gained from previous solved problems and they are used as a guide to solve the new problems [10] .CBR model is done in one cycle. Problem solving methods in this model includes four main step:

1- Retrieve similar case with new problem.

2- Use similar retrieved problem to provide proposed response for new problem.

3- Revision proposed response, if there is a discrepancy between conditions of new problem and retrieved problem.

4- save new problem and its answer for future use [11].

Each "case" express characteristics of related problem with itself. The second part, includes answer of considered problem. Specification of a "case" is determined by its attributes, and values that assigned to these attributes show situation of that case.

When a new problem is stated its situation is compared to previous solved problems. By using specific mechanisms most similar previous cases are retrieved. Retrieved cases are used to answer new problem. Then proposed response is provided. Proposed answer will be revisited by considering of new problem. Finally, new case (the raised problem) and its response will be maintain for future use in "case reservoir ". Figure 1 shows life cycle of this model. Range of use of CBR methods is wide such as identifying defects, diagnosing diseases, production scheduling, marketing plans and etc. [12]. [10].

Equation (1) shows general algorithm of this model

$$
\frac{\sum_{i=1}^{n} w_{i} * \operatorname{sim}\left(f_{i}^{I}, f_{i}^{R}\right)}{\sum_{i=1}^{n} w_{i}}
$$

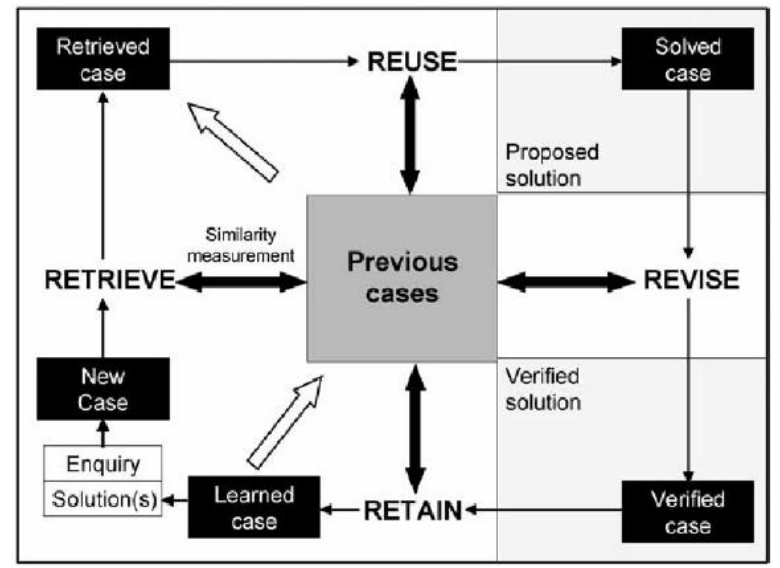

Fig.1. Modelling the CBR Life Cycle

Where $\mathrm{w}_{\mathrm{i}}$ is weight or value of any attribute. Which can get values between zero and 1 and Indicates relative importance of expert's view.

And sim (Old case, New Case) calculate similarity between new input attribute and old entrances.

$$
\mathrm{n}=\text { number of attributes of the sample. }
$$

To derive weight of expert opinion for qualitative values, we asked them to enter relative importance of each pair of attribute based on the Likert-scale in Paired comparisons tables. Relative importance of each attribute will be achieved after finalization of values of paired comparisons and normalizing results table. Expert Choice is one of the most important software that deals with analysis of paired comparisons tables. It can be used for similar equations too.

\section{RFID}

RFID stands for radio frequency identification and describes use of radio frequency signals to provide automatic identification [13].The system receives information about a person or characteristic of products as ID and it is saved in tag that contains a small processor and connected to a coil (antenna card ).A card reader communicates with tag and reads its ID.

RFID systems consist of following part: tags, readers, and backend servers. Figure 2 shows an example of a RFID tag.

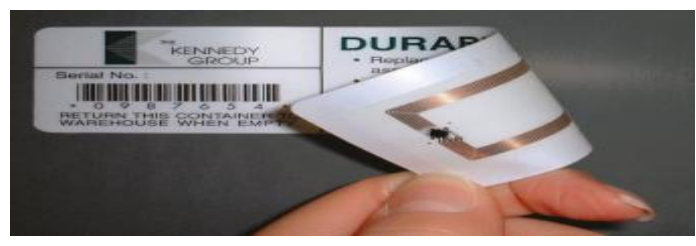

Fig.2. An example of the RFID tag 
Due to increase use of RFID systems in production and supply of products, impact of this technology has appear in supply chains. Four obvious benefits of RFID technology in supply chain are:

- Automation, $\bullet$ high production rate, $\bullet$ Ability to monitor all stages of supply, $\bullet$ improve business insight.

Each stage of the supply chain can be tracked and monitored by RFID tags [14].

RFID can provide product information for customers via mobile devices such as mobile phones and tablets. And it provides helpful features in product life cycle management software such as:

1. There is no possibility of failure in product information.

2. Customer has access to the necessary information according to standard of the food industry.

3. Automatic control of entry and exit of goods to warehouse and accounting system is possible.

4. Immediate information of product sales will be reported to factory.

5. There is possibility to send reports of customer dissatisfaction to the factory [15].

\section{PRopose A NeW Model}

General framework of proposed model is presented in this section. Steps of this model are:

Step 1: HACCPs of previous products are recorded.

Step 2: Chemical and physical attributes of new products are determined.

Step 3: Study of similar attribute based on qualitative values that are obtained by paired comparison tables. Then quantitative values will obtain based on similarity equations.

Step 4: Similar products are retrieved by using CBR search engine.

Step 5: HACCP of retrieved products is reviewed and is edited by an expert.

Step 6: HACCP of products is saved in database then it will be used in subsequent decisions.

Step 7: Customers can be enable to use this guide by using RFID tags.

Figure 3 is physical structure of network system that shows relationship between hardware and software components. This system is divided into four parts:

1. The central database system.

2. Additional attribute to introduce products through RFID.

3. Sale management system to report what are submitted.

4. Data mining and processing of sales history.

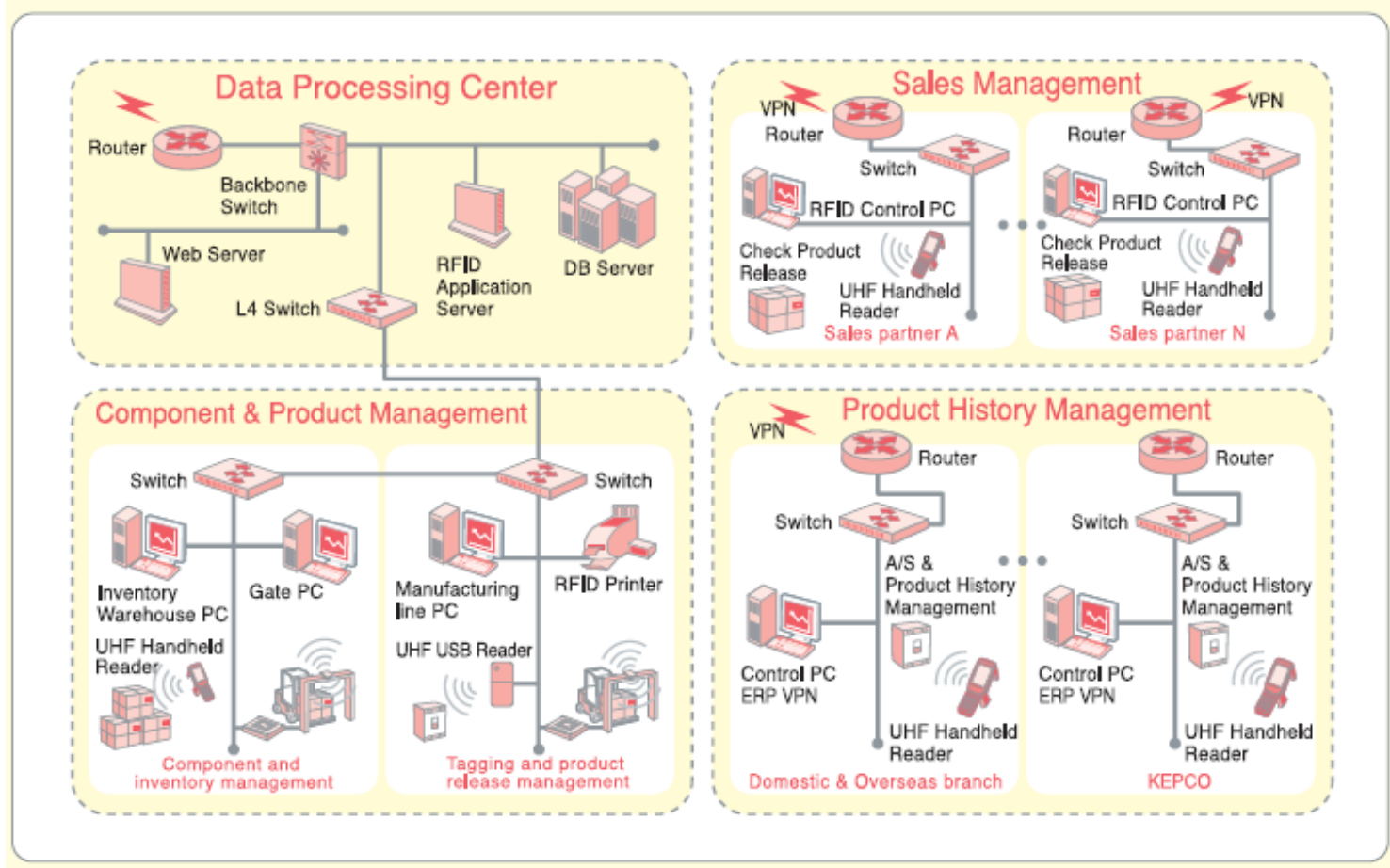

Fig.3. Structure of product lifecycle management system by RFID technology

\subsection{Establishing a repository for products and their HACCP:}

First and second step in this research study details of the Sabz Nam Company's food.

In this company dried fruit and seeds are packed and information of 80 product are investigated.

Figure 4 shows database of the system where alarm 
tables, vendor, reports, sales and services is used to communicate with their customers. And food safety table is used in CBR search engine. Attributes of food safety table are used as make-decision input parameters in CBR engine. Number of these attribute are equal to $n$ in equation (1). Figure 5 shows it.

In the third step, expert's opinion is used for amount of influence on search process. It is given value between zero and one, according to table 1 . Value of $\mathrm{Wi}$ is determined in similarity equation.
Table 1. The amount of Rankings

\begin{tabular}{|c|c|}
\hline value & ranking \\
\hline 0.9 & Very important \\
\hline 0.6 & important \\
\hline 0.4 & Less important \\
\hline 0.2 & No idea \\
\hline 0.1 & Not important \\
\hline
\end{tabular}

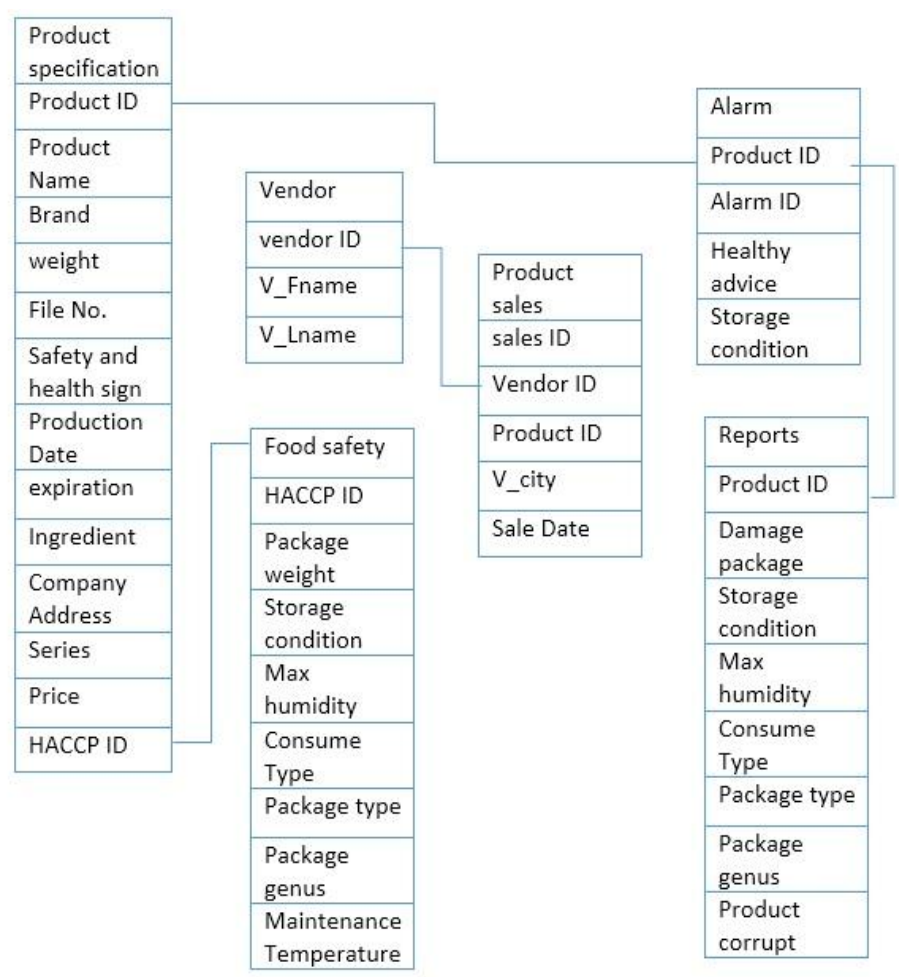

Fig.4. The database of the system

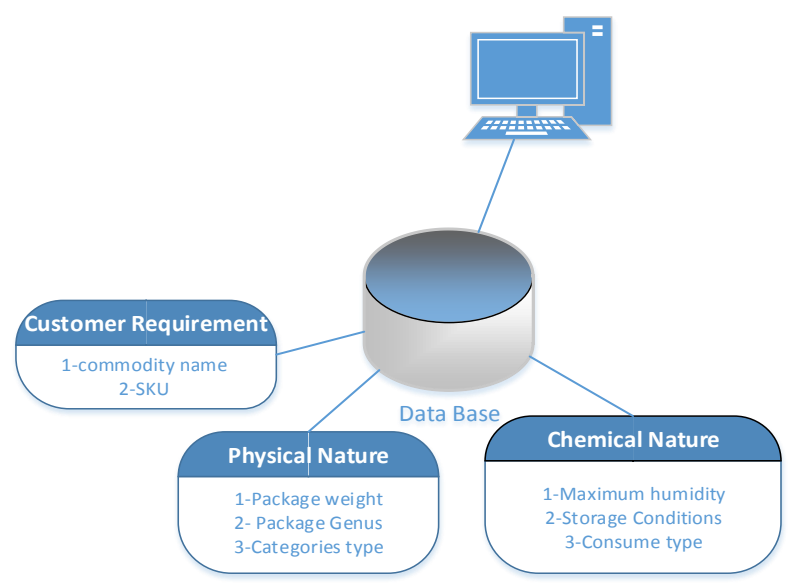

Fig.5. Classification of HACCP parameters

The fourth step retrieve information by CBR search engine. One of the most complex aspects of CBR is how to calculate similarity of new problem based on input parameters and compare to previous problem. Most methods use Nearest Neighbor function to calculate similarity. In these methods measure amount of similarity in new problem then compare it to previous problem, in relation with each metrics of similarity and then mean of value is calculated by equation (1).

We calculate amount of similarity for quality values based on tables $(2,3,4,5)$. Sim (Old case, New Case) is used for parameters of consume type, genus packaging 
and type of packing and storage condition. Equation (2) is used for: packaging weight, maximum humidity and temperature maintenance.

$$
\operatorname{Sim}(\text { Old Case, New case })=1-\frac{|A-B|}{h-l}
$$

In Equation $2 \mathrm{~h}$ is the maximum and the 1 is equal to minimum. Table 6 shows Values $h$ and 1.

Table 2. Paired comparisons, parameter storage conditions

\begin{tabular}{|c|c|c|c|c|c|}
\hline \multicolumn{7}{|c|}{ Storage conditions } \\
\hline Frozen & Refrigerator & Normal & $\begin{array}{c}\text { Warm } \\
\text { and dry }\end{array}$ & $\begin{array}{c}\text { Cool } \\
\text { and dry }\end{array}$ \\
\hline Frozen & 1 & 0.7 & 0.08 & 0.05 & 0.2 \\
\hline $\begin{array}{c}\text { Refrige } \\
\text { rator }\end{array}$ & - & 1 & 0.2 & 0.1 & 0.4 \\
\hline Normal & - & - & 1 & 0.6 & 0.1 \\
\hline $\begin{array}{c}\text { Warm } \\
\text { and dry }\end{array}$ & - & - & - & 1 & 0.3 \\
\hline $\begin{array}{c}\text { Cool } \\
\text { and dry }\end{array}$ & - & - & - & - & 1 \\
\hline
\end{tabular}

Table 3. Paired comparisons, Parameters of Category

\begin{tabular}{|l|c|c|c|}
\hline \multicolumn{4}{|c|}{ Packaging type } \\
\hline & Piece & Sharing & Carton \\
\hline Piece & 1 & 0.1 & 0.3 \\
\hline Sharing & - & 1 & 0.6 \\
\hline Carton & - & - & 1 \\
\hline
\end{tabular}

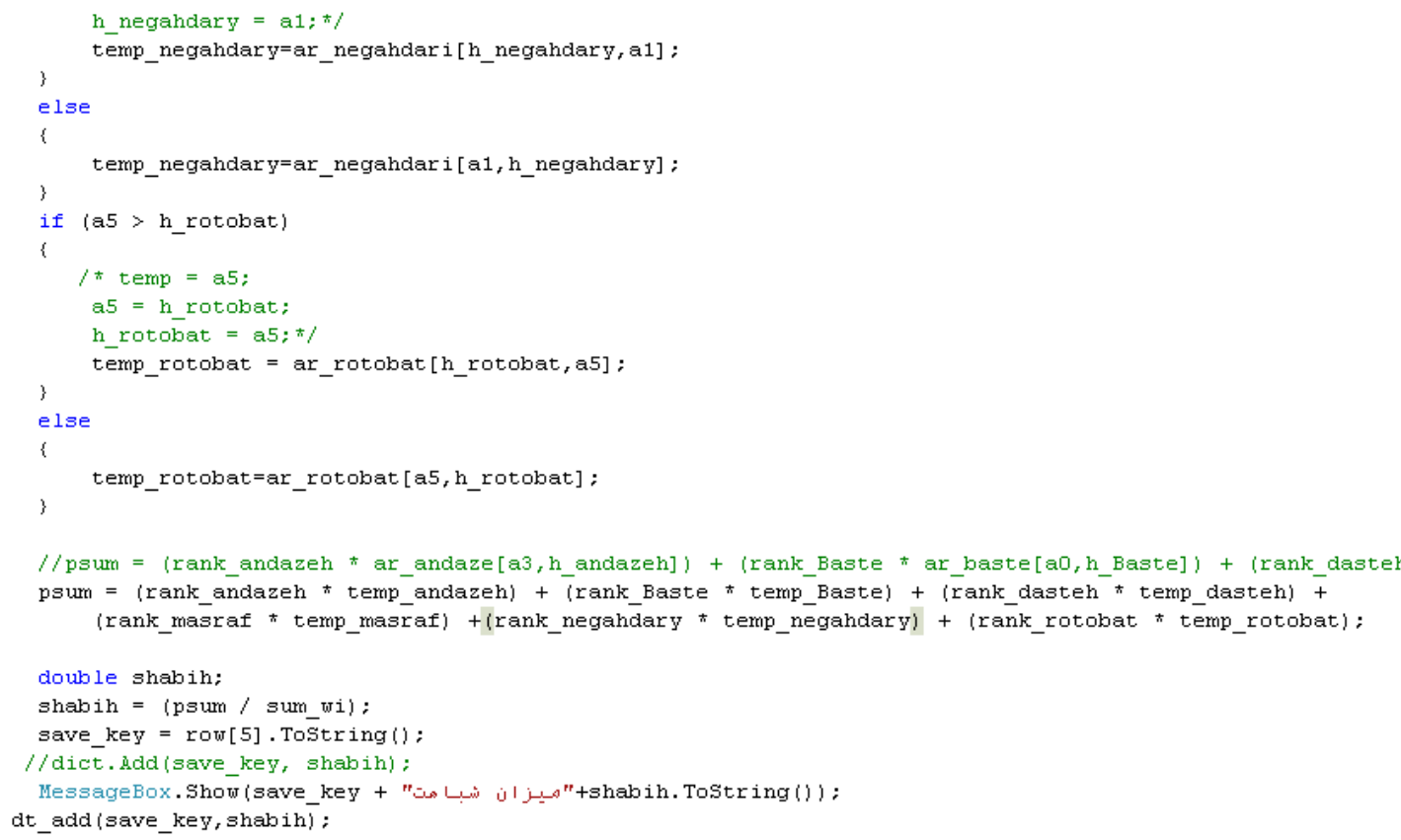

Fig.6. Code has written in $\mathrm{C}$ \# for search engine

\subsection{One solved example}

In this example characteristics of new products and importance of decision are determined by experts. 
Similarity between new product and exist products obtained from database Then by using equations 1 and 2 .

$$
\begin{aligned}
& \frac{\sum_{i=1}^{n}{ }^{w_{i}}{ }^{*} \operatorname{sim}(A, B)}{\sum_{i=1}^{n}{ }^{w}{ }_{i}} \\
& =\frac{0.3 * 1+0.7 * 0.98+0.7 * 1+0.7 * 1+0.3 * 0.97+0.55 * 1+0.55 * 0.88}{0.3+0.7+0.7+0.7+0.3+0.55+0.55}=
\end{aligned}
$$$$
0.82 * 100=82 \%
$$

Amounts of new products, expert's opinions and attribute of previous products have shown in Table 7.

We enter primary information in to the software and then search engine give its recommendation after examining. Figure7 and 8 show picture of software environment. This software has written in C\# .NET 2010 and SQL SERVER 2010.

Table 7. Shows Comparison between old items with new items

\begin{tabular}{|l|l|c|c|c|c|}
\hline Attribute types & Rate & Value of $\mathrm{w}_{\mathrm{i}}$ & Old Case & New Case & $\begin{array}{l}\text { Rate of similarity } \\
\text { sim(Old Case, NewCase) }\end{array}$ \\
\hline Package genus & Less important & 0.3 & Cellophane & Cellophane & 1 \\
\hline Maximum humidity & Very important & 0.7 & 7 & 9 & $1-\frac{9-7}{25}=.98$ \\
\hline Storage conditions & Very important & 0.7 & Cool and dry & Cool and dry & 1 \\
\hline Consume type & Very important & 0.7 & additive & additive & 1 \\
\hline Package weight & less important & 0.3 & 100 & 150 & $1-\frac{150-100}{1875}=.97$ \\
\hline Categories & important & 0.55 & Carton & Carton & 1 \\
\hline Temperature & important & 0.55 & 10 & 13 & $1-\frac{13-10}{25}=.97$ \\
\hline
\end{tabular}

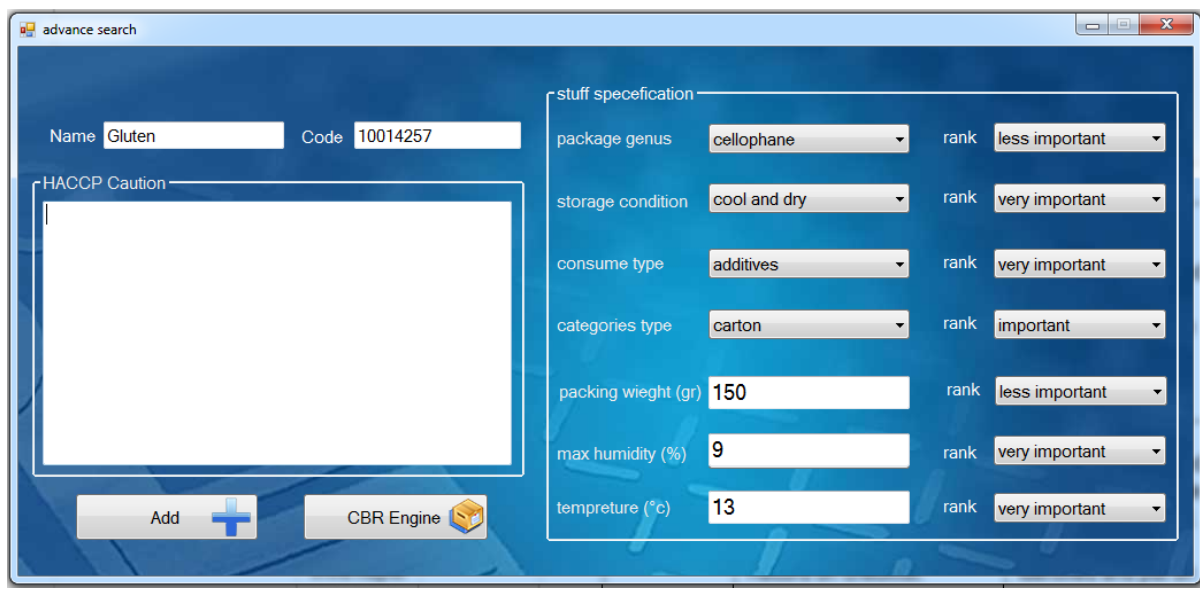

Fig.7. New specifications and pricing for Search

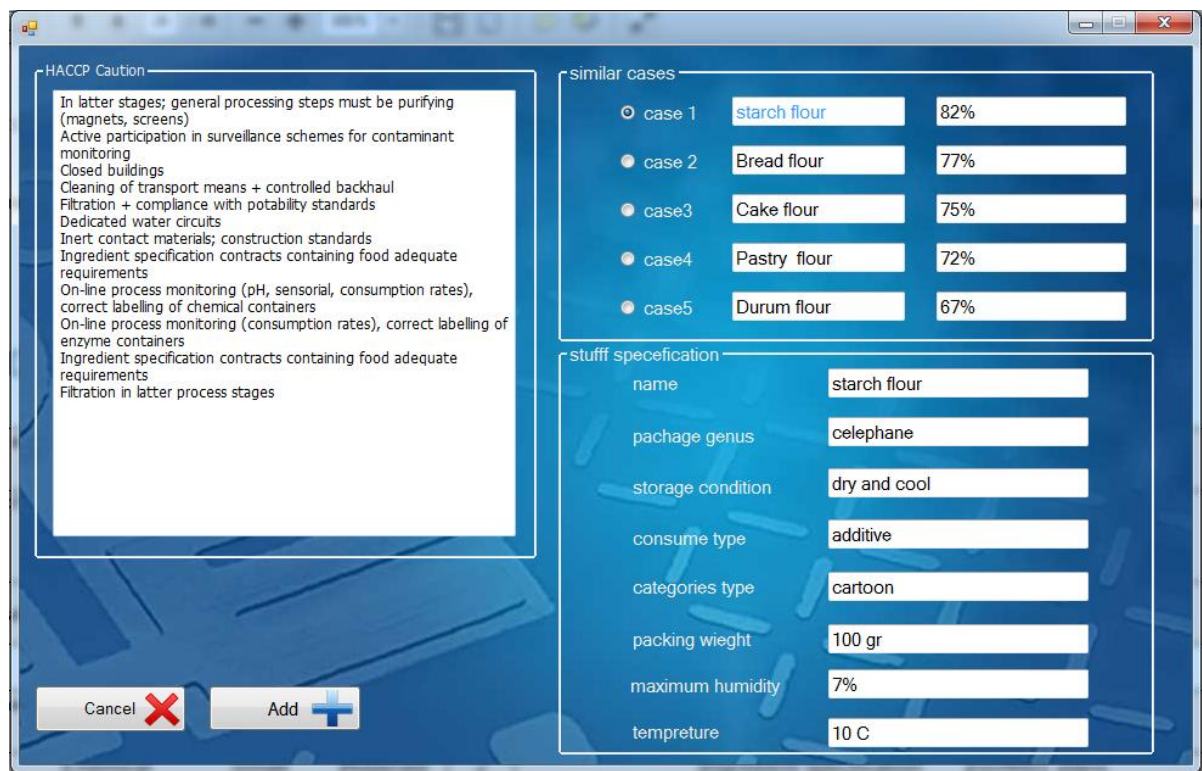

Fig.8. Prioritized recommendations expert system to expert 


\subsection{Assessment}

In order to ensure of accuracy of functioning of the proposed system, we used actual data set of company.

In this regard, various tests and studies was performed and will come in the following:

Study of sample recovery Accuracy: This means that if a sample of samples library was called, system must deliver sample with similarity equal to $100 \%$.

Study compatibility of recovery: Same samples with same equal accuracy are retrieved. If an activity with the same search is performed twice.

\section{CONCLUSION}

The main goal of this study is to design and implement HACCP in "Sabz Nam" company. And it can be new step in food industry of Iran. We used Case Base Reasoning and implemented it via new proposed model and showed its results in this paper. This system reduced cost of learning and training staffs. As well as it is good solution in food regulatory system. Use of RFID technology to provide company products information for customers is one of the advantages of these system. And it increased their satisfaction. In future research can enhance accuracy and speed of model by using optimization algorithms.

\section{ACKNOWLEDGMENT}

This paper derived from research project "presenting a new approach in food safety management using a combination of case based reasoning models and data mining methods". Done in Abadan Branch, Islamic Azad University, Abadan, Iran.).

\section{REFRENCE}

[1] Nilsson, L., Johnson, M. D., \& Gustafsson, A. (2001). The impact of quality practices on customer satisfaction and business results: Product versus service organizations. Journal of Quality Management, 6, 5-27.

[2] Orriss, G. D., \& Whitehead, A. J. (2000). Hazard analysis and critical control point (HACCP) as a part of an overall quality assurance system in international food trade. Food Control, 11, 345-351.

[3] Erkoc, M., Iakovouand, E. T., \& Spaulding, A. E. (2005). Multi-stage onboard inventory management policies for food and beverage items in cruise liner operations. Journal of Food Engineering, 271, 269-279

[4] Trienekens, J., \& Zuurbier, P. (2007). Quality and safety standards in the food industry, developments and challenges. International Journal of Production Economics, 113, 107-122.

[5] Yan, Z., Sousa-Gallagher, M. J., \& Oliveira, F. A. R. (2008). Identification of critical quality parameters and optimal environment conditions of intermediate Moisture content banana during storage. Journal of Food Engineering, 85, 163-172.

[6] Westenbrink, S., Oseredczuk, M., Castanheira, I., \& Roe, M. (2009). Food composition databases: EuroFIR approach to develop tools to assure the quality of the data compilation process. Food Chemistry, 113, 759-767.

[7] Getinet, H., Seyoum, T., \& Woldetsadik, K. (2008). The effect of cultivar, maturity stage and storage environment on quality of tomatoes. Journal of Food Engineering, 87, 467-478.

[8] H.Y. Lam, K.L. Choy ^, G.T.S. Ho, C.K. Kwong, C.K.M Lee,(2013) A real-time risk control and monitoring system for incident handling in wine storage,3665-3678

[9] S.I. Lao, K.L. Choy 爪, G.T.S. Ho, Y.C. Tsim, T.C. Poon, C.K. Cheng,(2012) A real-time food safety management system for receiving operations in distribution centers 2532-2539

[10] Castro, J. L., Navarro, M., Sanchez, J. M., \& Zurita, J. M. (2011). Introducing attribute risk for retrieval in casebased reasoning. Knowledge-Based Systems, 24(2), 257268.

[11] Chou, J. S. (2009). Web-based CBR. system applied to early cost budgeting for pavement maintenance project. Expert Systems with Applications, 36, 2947-2960.

[12] Chow, H. K. H., Choy, K. L., Lee, W. B., \& Lau, K. C. (2006). Design of a RFID case-based resource management system for warehouse operations. Expert Systems with Applications, 30(4), 561-576.

[13] Kwok, S. K., \& Wu, K. K. W. (2009). RFID-based intrasupply chain in textile industry. Industrial Management \& Data System, 109(9), 1166-1178.

[14] Poon, T. C., Choy, K. L., Chow, H. K. H., Lau, H. C. W., Chan, F. T. S., \& Ho, K. C. (2009). A RFID case-based logistics resource management system for managing order pick operations in warehouses. Expert Systems with Applications, 36, 8277-8301.

[15] Abad, E., Palacio, F., Nuin, M., González de Zárate, A., Juarros, A., Gómez, J.M., Marco, S., 2009. RFID smart tag for traceability and cold chain monitoring of foods:demonstration in an intercontinental fresh fish logistic chain. Journal of Food .Engineering 93 (4), 394 399 .

\section{Authors' Profiles}

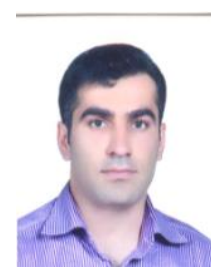

Sasan Saqaeeyan was born on 1984.He received the BS degree in computer software engineering in 2008 from the University of Isfahan and MS degree in computer software engineering in January 2010, from the Islamic Azad University Khoozestan Science and Research Branch, Iran. From January 2011 he has worked in the Islamic Azad University Abadan Branch as a Faculty Member.

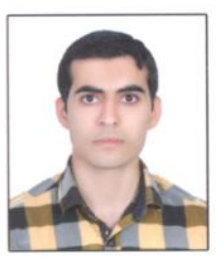

Ali Rismantab was born on 1987.He received the BS degree in computer software engineering in 2010 from the University of Payamnoor and MS degree in computer software engineering in January 2014, from the Islamic Azad University Shahrood Science and Research Branch, Iran. From January 2014 he has worked in Sama technical and vocational training college Islamic Azad University, Shushtar Branch. 